\title{
Alzheimer's disease and frontotemporal dementia are differentiated by discriminant analysis applied to ${ }^{99 \mathrm{~m}} \mathrm{Tc} \mathrm{HmPAO}$ SPECT data
}

\author{
P Charpentier, I Lavenu, L Defebvre, A Duhamel, P Lecouffe, F Pasquier, M Steinling
}

\begin{abstract}
Objective-Alzheimer's disease (AD) and frontotemporal dementia (FTD) are the most frequent neurodegenerative cognitive disorders. However, FTD remains poorly recognised clinically. The use of ${ }^{99 m}$ HmPAO-single photon emission computed tomography (SPECT) has been demonstrated in the differentiation of $\mathrm{AD}$ and FTD. Nethertheless, there are very few comparative studies designed to assess its precise value in this differential diagnosis. The aim was to determine a simple decision rule, deduced from statistical analysis, which, if applied to regions of interest (ROIs) and mini mental state examination (MMSE), could improve the predictive value of SPECT in differential diagnosis between AD and FTD.
\end{abstract}

Methods-Forty patients, 20 with probable AD and 20 with probable FTD were included. All patients underwent brain SPECT imaging, after an intravenous injection of ${ }^{99 \mathrm{~m}} \mathrm{Tc} \mathrm{HmPAO}-(555 \mathrm{mBq})$. For each patient, 20 ROIs were determined on the Fleishig's slice and their activity was normalised to the mean cerebellar activity. Bivariate analysis (Wilcoxon rank tests) and multivariate analysis (stepwise discriminant analysis) were performed to determine the subgroup of variables able to give the highest predictive value for this differential diagnosis. A simple decision rule was built from a predictive score derived by factorial discriminant analysis. Results-As previously described, the fixation defect was found in frontal regions of interest (ROIs) in FTD and in the left temporoparietal-occipital ROIs in AD. Among the 21 variables, five were finally selected: right median frontal, left lateral frontal, left tempoparietal, left temporoparietal-occipital areas, and MMSE. One hundred per cent of patients with FTD were correctly classified by the decision rule (20/20 patients) and $90 \%$ of patients with AD (18/20).

Conclusion-AD and FTD are differentiated by SPECT. Automatic classification based on a decision rule deduced from factorial discriminant analysis could enhance its performance.

(F Neurol Neurosurg Psychiatry 2000;69:661-663)

Keywords: Alzheimer's disease; frontotemporal degeneration; SPECT; discriminant analysis

The frontotemporal dementia (FTD) concept still needs clinical and non-clinical tools to enable better discrimination. The main differential diagnosis remains Alzheimer's disease (AD). According to the Lund and Manchester criteria, ${ }^{1}$ FTD is a clinical designation, applied to a progressive behavioural disorder associated with primary degeneration of the frontal and the temporal lobes. Decreasing regional perfusion shown by SPECT indicates impaired function in specific cortical areas, and this correlates with clinical, ${ }^{2}$ neuropsychological, ${ }^{3}$ and histopathological ${ }^{4}$ findings. Usually, the perfusion pattern is assessed qualitatively by visual inspection and by semiquantitative analysis. Morover, the studies are usually designed to clarify the functional pattern and not to compare specifically the regional cerebral blood flow (rCBF) in $\mathrm{AD}$ versus FTD. However, this approach seems to be necessary to establish the statistical value of the SPECT data in differential diagnosis.

The aim of this study was (1) to specify the contribution of ${ }^{99 \mathrm{~m}} \mathrm{Tc}$ HmPAO SPECT in the differential diagnosis between FTD and AD by using statistical analysis; (2) to search for a possible decision rule leading to a differential classification of these two types of dementias, deduced from multivariate analysis applied to SPECT data and mini mental state examination (MMSE) score.

\section{Patients and methods}

PATIENTS

We included 40 patients in this study, 20 with probable FTD and 20 with probable AD. They were selected and followed up in the Memory Clinic Centre. The Lund and Manchester ${ }^{1}$ criteria were fulfilled by patients with FTD and NINCDS-ADRDA ${ }^{5}$ criteria by patients with AD. Patients were excluded when other chronic neurological or non-neurological disorder was detected, and CT or MRI was performed for all of them. Patients with strokes 
or other vascular lesions were also excluded. All of the selected patients were investigated with a comprehensive battery of neuropsychological tests $^{6}$ including MMSE. ${ }^{7}$ The two groups differed in MMSE score (17.8 (SD 7.4) in AD $v 23.5$ (SD 5) in FTD), duration of the disease (6.2 (SD 2.4) years $v 3.3$ (SD 1.7)), and age (71.4 (SD 5.2) $v 64.5$ (SD 6.5)). This was expected as these differences are included in the diagnosis criteria for FTD and AD: the age of onset is younger in FTD than in $\mathrm{AD}$, difference in MMSE is linked to the later memory and language impairment in FTD compared with AD. To approach as close as possible to current practice conditions, we have chosen to include patients during their first year of follow up in our memory centre. This is implying that they were preselected people, belonging to a population with these specific clinical patterns.

\section{METHODS}

Brain SPECT was done after an intravenous injection of $550 \mathrm{mBq}{ }^{99 \mathrm{~m}} \mathrm{Tc} \mathrm{HmPAO}$. The method for SPECT acquisition and for the design of ROIs as well as statistical methodology is detailed in a previous article by Defebvre et al..$^{8}$

Ten pairs of regions of interest (ROIs) were drawn on the slice located $50 \mathrm{~mm}$ above the orbitomeatal plane determined according to the Cabanis atlas. The ROIs were the left and right medial-frontal (Med-Fr), lateral-frontal (Lat-Fr), posterior-frontal (Post-Fr), temporal and insular (Temp-Ins), temporal and parietal (Temp-Par), temporo-parieto-occipital junction (Temp-Par-Occ), parieto-occipital (ParOcc), occipital (Occ), lenticular nucleus (lentnuc), and thalamus (Thal).

\section{STATISTICAL ANALYSIS}

Statistical tests were made at the 0.05 level. Because of the size of the groups $(<30)$, the individual predictive value of each index related to the 10 pairs of ROIs and to the MMSE score was first examined by a Wilcoxon rank test. A factorial discriminant analysis (FDA) was performed over the variables having a significance level less than $15 \%$. Factorial discriminant analysis is a multivariate statistical procedure that uses a set of explanatory variables to classify patients into different subgroups and allows the construction of a new variable-namely, the predictive score. This score maximises the ratio of the variability between the groups to the variability within the groups and therefore patients of different groups have score values as different as possible. The score was used to determine a prediction rule. Subsequently, to select a best subset of predictor variables, a final stepwise discriminant analysis was performed (at level $15 \%$ and with "stepwise" option which is a forward selection allowing elimination). ${ }^{8}$

\section{Results}

The table gives the result of the group comparison. For the multivariate analysis, five ROIs were excluded because $\mathrm{p}$ was greater than 0.15 (L lent-Nuc, R Occ, L Occ, L Thal, and R Thal) leading to the selection of 16 variables.

In a first step, the FDA was performed on these 16 variables (MMSE score and 15 indexes). All of them showed a very good separation between the two groups by means of the discriminant score $\left(r^{2}\right.$ ratio 0.78$)$. Among the 40 patients, 38 (95\%) were correctly classified. After the stepwise discriminant analysis, the following predictor variables were definitively retained: R Med-Fr, MMSE, L Temp-ParOcc, L Post-Fr, and L Temp-Ins. A second FDA was performed on these five remaining variables. The final score was calculated as follows:

$\mathrm{S}=6.1 \times(\mathrm{R}$ Med-Fr $)-9.8 \times(\mathrm{MMSE} / 100)-12.3 \times$ (L Temp-Par-Occ) $+9.6 \times(\mathrm{L}$ Lat-Fr $)+9.6 \times(\mathrm{L}$ Temp-Par)-9.1

The figure represents the distribution of the discriminant score by status (AD or FLD). This graphic demonstrates that the subset of five variables seemed to be relevant for predicting diagnosis. Then, from the figure a decision rule was derived: if $S<0$, then diagnosis proposed is FTD, and if $S \geqslant 0$, the diagnosis proposed is $\mathrm{AD}$.

Using this decision rule, $100 \%(20 / 20)$ of patients with FLD and $90 \%$ (18/20) of patients with $\mathrm{AD}$ were classified in the correct group.

Fixation index (mean (SD)) of each region of interest in the two groups ( $A D$ v FTD)

\begin{tabular}{|c|c|c|c|c|c|c|c|}
\hline$R O I$ & $L \mathrm{Med}-\mathrm{Fr}$ & L Lat-Fr & $L$ Post-Fr & L Temp-Ins & L Temp-Par & L Temp-Par-Occ & $L$ Par-Occ \\
\hline $\mathrm{AD}$ & $\begin{array}{l}0.841(0.067) \\
{[0.835]}\end{array}$ & $\begin{array}{l}0.828(0.074) \\
{[0.835]}\end{array}$ & $\begin{array}{l}0.871(0.07) \\
{[0.85]}\end{array}$ & $\begin{array}{l}0.842(0.011) \\
{[0.85]}\end{array}$ & $\begin{array}{l}0.875(0.075) \\
{[0.865]}\end{array}$ & $\begin{array}{l}0.775(0.012) \\
{[0.745]}\end{array}$ & $\begin{array}{l}0.794(0.011) \\
{[0.78]}\end{array}$ \\
\hline FTD & $\begin{array}{l}0.795(0.066) \\
{[0.786]}\end{array}$ & $\begin{array}{l}0.769(0.05) \\
{[0.771]}\end{array}$ & $\begin{array}{l}0.822(0.062) \\
{[0.829]}\end{array}$ & $\begin{array}{l}0.881(0.045) \\
{[0.873]}\end{array}$ & $\begin{array}{l}0.839(0.053) \\
{[0.839]}\end{array}$ & $\begin{array}{l}0.875(0.056) \\
{[0.883]}\end{array}$ & $\begin{array}{l}0.86 .2(0.078) \\
{[0.859]}\end{array}$ \\
\hline $\mathrm{p}$ Value & $\begin{array}{l}0.003 \\
\text { L Occ }\end{array}$ & $\begin{array}{l}0.001 \\
\text { L Lent-Nuc }\end{array}$ & $\begin{array}{l}0.06 \\
\text { L Thal }\end{array}$ & $\begin{array}{l}0.14 \\
\text { R Med-Fr }\end{array}$ & $\begin{array}{l}0.14 \\
\text { R Lat-Fr }\end{array}$ & $\begin{array}{l}0.004 \\
\text { R Post-Fr }\end{array}$ & $\begin{array}{l}0.02 \\
\text { R Temn-Ins }\end{array}$ \\
\hline $\mathrm{AD}$ & $\begin{array}{l}97.4(7.2) \\
{[0.965]}\end{array}$ & $\begin{array}{l}0.948(0.067) \\
{[0.935]}\end{array}$ & $\begin{array}{l}0.879(0.064) \\
{[0.87]}\end{array}$ & $\begin{array}{l}0.853(0.073) \\
{[0.85]}\end{array}$ & $\begin{array}{l}0.836(0.065) \\
{[0.84]}\end{array}$ & $\begin{array}{l}0.878(0.057) \\
{[0.87]}\end{array}$ & $\begin{array}{l}0.889(0.083) \\
{[0.889]}\end{array}$ \\
\hline FTD & $\begin{array}{l}98.8(5.8) \\
{[0.989]}\end{array}$ & $\begin{array}{l}91.5(0.068) \\
{[0.913]}\end{array}$ & $\begin{array}{l}0.869(0.054) \\
{[0.879]}\end{array}$ & $\begin{array}{l}0.755(0.071) \\
{[0.754]}\end{array}$ & $\begin{array}{l}0.785(0.046) \\
{[0.781]}\end{array}$ & $\begin{array}{l}0.824(0.061) \\
{[0.821]}\end{array}$ & $\begin{array}{l}0.906(0.047) \\
{[0.91]}\end{array}$ \\
\hline $\mathrm{p}$ Value & $\begin{array}{l}\text { NS } \\
\text { R Temp-Par }\end{array}$ & $\begin{array}{l}\text { NS } \\
\text { R Par-Occ }\end{array}$ & $\begin{array}{l}\text { NS } \\
\text { R Occ }\end{array}$ & $\begin{array}{l}0.0005 \\
\text { R Temp-Par-Occ }\end{array}$ & $\begin{array}{l}0.003 \\
\text { R Lent-Nuc }\end{array}$ & $\begin{array}{l}0.008 \\
\text { R Thal }\end{array}$ & 0.12 \\
\hline $\mathrm{AD}$ & $\begin{array}{l}0.884(0.06) \\
{[0.875]}\end{array}$ & $\begin{array}{l}0.817(0.010) \\
{[0.795]}\end{array}$ & $\begin{array}{l}0.988(0.074) \\
{[0.99]}\end{array}$ & $\begin{array}{l}0.821(0.010) \\
{[0.815]}\end{array}$ & $\begin{array}{l}0.956(0.061) \\
{[0.95]}\end{array}$ & $\begin{array}{l}0.88(0.066) \\
{[0.885]}\end{array}$ & \\
\hline FTD & $\begin{array}{l}0.852(0.048) \\
{[0.851]}\end{array}$ & $\begin{array}{l}0.873(0.067) \\
{[0.872]}\end{array}$ & $\begin{array}{l}0.998(0.038) \\
{[0.997]}\end{array}$ & $\begin{array}{l}0.889(0.058) \\
{[0.891]}\end{array}$ & $\begin{array}{l}0.915(0.052) \\
{[0.921]}\end{array}$ & $\begin{array}{l}0.874(0.051) \\
{[0.872]}\end{array}$ & \\
\hline $\mathrm{p}$ Value & 0.013 & 0.02 & NS & 0.02 & 0.03 & NS & \\
\hline
\end{tabular}

Fixation index is defined as a fraction of mean cerebellar fixation. Median [M] and significance after Wilcoxon's rank test (p) are calculated for each region of interest. The $\mathrm{p}$ value is considered significant at $\mathrm{p}<0.15$. Five non-discriminative (NS) variables were eliminated after the initial bivariate analysis.

L=Left; R=right; Med-Fr=medial-frontal; Lat-Fr=lateral-frontal; Post-Fr=posterior-frontal); Temp-Ins=temporal and insular; Temp-Par =temporal and parietal; Temp-Par-Occ=temporoparietal occipital junction; Par-Occ=parieto-occipital; Occ=occipital; Lent-Nuc=lenticular nucleus; Thal=thalamus). 


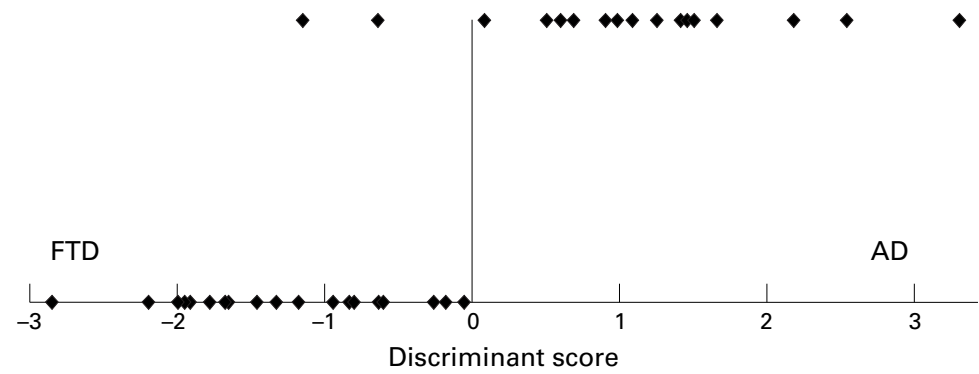

Discriminant score by disease.
- $\quad \mathrm{AD}^{10}$ and other clinical and neuropsychological criteria are necessary to distinguish these patients. Nevertheless, relatively low fixation levels predominating in frontal, temporal, and limbic areas and basal ganglia are found in normal elderly people compared with younger people. ${ }^{17}$ This infers that a slight frontal defect may not have pathological significance in $\mathrm{AD}$ as a frontal defect seen in AD could be linked to this "physiological" phenomenon. In other words, the emerging concept of dementia with Lewy bodies could lead to a blackballing of the usual approach based on binary differential diagnosis between FTD and AD. Finally, our proposition of an algorithm deduced from stepwise logistic regression could simplify the road to diagnosis when the precise question is: "Is this disease AD or FTD?". Visual analysis, which is subjective and depends on the examiner, is usually not completed by a decision rule deduced from discriminant analysis for differential diagnosis of $\mathrm{AD}$ and FTD. We conclude that discriminant analysis can provide objective information which helps the examiner to establish the final positive diagnosis. Nethertheless, further studies are required to validate this tool. criteria of $\mathrm{AD} .{ }^{10}$ Other criteria are necessary for the differential diagnosis.

Since the end of the 1980s, many studies have confirmed the usefulness of ${ }^{99 \mathrm{~m}} \mathrm{HmPAO}-$ SPECT in these diseases. ${ }^{11}{ }^{12}$ Between FTD and $\mathrm{AD}$, frontal anterior and parieto-occipital hypoperfusions are known to be easily distinguishable and to constitute a reliable paraclinical tool for identifying these diseases. In a multivariate correlative study derived from OPTIMA, Jobst et $a l^{4}$ reported a good correlation between clinical, ${ }^{99 \mathrm{~m}} \mathrm{Tc}-\mathrm{HmPAO}-\mathrm{SPECT}$, and neuropathological findings in AD. A close coupling between reduced $\mathrm{rCBF}$ and specific neuropsychological deficits in $\mathrm{AD}^{13}$ and $\mathrm{FTD}^{14}$ was also shown. In our study, in agreement with these previous data, the lateral and internal frontal ROIs were hypoperfused in cases of FTD, at a high significance level.

Pickut et al have applied discriminant analysis to the differential diagnosis between $\mathrm{AD}$ and FTD with SPECT. ${ }^{15}$ They also proposed an algorithm which gives the probability for $\mathrm{AD}$ or FTD, but in their approach frontal hypoperfusion was the only SPECT data kept in the final decision rule. Miller et al, using the SPECT data as the gold standard for the diagnosis of FTD,${ }^{16}$ identified the best items of the Lund and Manchester criteria by applying a stepwise logistic regression analysis to these criteria for DTF diagnosis. They suggested that only five clinical criteria selected from among those of Lund and Manchester were as efficient as all of them for positive diagnosis of FTD. Although the clinical definition of FTD seems to be well established, it does not exclude disorders that may also affect frontotemporal structures such as $\mathrm{AD}$. In our study, two patients with $\mathrm{AD}$ were wrongly classified in the FTD group, but clinical possibilities of overlap are possible at the beginning of the illness. ${ }^{9}$ Our two wrongly classified patients could belong to this group. Patients with FTD usually fulfill the NINCDS-ADRDA criteria of
1 Neary D, Snowden JS, Gustafson L, et al. Frontotemporal lobar degeneration: a consensus on clinical diagnostic criteria. Neurology 1998;51:1546-54.

2 Jagust WJ, Reed BR, Seab JP, et al. Clinical-physiologic correlates of Alzheimer's disease and frontal lobe dementia. Am $\mathcal{F}$ Physiol Imaging 1989;4:89-96.

3 Elfgren CI, Ryding E, Passant U. Performance on neuropsychological tests related to single photon emission computerised tomography findings in frontotemporal dementia. Br f Psychiatry 1996;169:416-22.

4 Jobst KA, Barnetson LP, Shepstone BJ. Accurate prediction of histologically confirmed Alzheimer's disease and the diferential diagnosis of dementia: the use of NINCDSADRDA and DSM-III-R criteria, SPECT, X-ray CT, and apo E4 in medial temporal lobe dementias. Oxford Project to Investigate Memory and Aging. Int Psychogeriatr 1998;10:271-302.

5 McKhann G, Drachman D, Folstein M, et al. Clinical diagnosis of Alzheimer's disease: report of the NINCDSADRDA work group under the auspices of Department of Health and Human Services Task Force on Alzheimer's Disease. Neurology 1984;34:939-44.

6 Pasquier F, Lebert F, Lavenu I, et al. The clinical picture of frontotemporal dementia: diagnosis and follow-up. Dement Geriatr Cogn Disord 1999;10(suppl 1):10-14

7 Folstein MF, Folstein SE, McHugh PR. Mini-mental state. A practical method for grading the cognitive state of patients for the clinician. F Psychiatr Res 1975;12:189-98.

Defebvre L, Leduc V, Duhamel A, et al. Technetium HMPAO SPECT study in dementia with Lewy bodies, Alzheimer's disease, and idiopathic Parkinson's disease. $f$

9 Litvan I, Agid Y, Sastry N, et al. What are the obstacles for an accurate clinical diagnosis of Pick's disease? A clinicopathologic study. Neurology 1997;49:62-9.

10 Varma AR, Snowden JS, Lloyd JJ, et al. Evaluation of the NINCDS-ADRDA criteria in the differentiation of Alzheimer's disease and frontotemporal dementia. $\mathcal{F}$ Neurol Neurosurg Psychiatry 1999;66:184-8.

11 Talbot PR, Lloyd JJ, Snowden JS, et al. A clinical role for ${ }^{99 \mathrm{~m}}$ Tc-HMPAO SPECT in the investigation of dementia? $\mathcal{F}$ Neurol Neurosurg Psychiatry 1998;64:306-13.

12 Pasquier F, Lavenu I, Lebert F, et al. The use of SPECT in a multidisciplinary memory clinic. Dement Geriatr Cogn Disord 1997;8:85-91.

13 Goldenberg G, Podreka I, Suess E, et al. The cerebral localization of neuropsychological impairment in Alzheimer's zation of neuropsychological impairment in Alzhe

14 Miller BL, Cummings JL, Villanueva-Meyer J, et al. Frontal lobe degeneration: clinical, neuropsychological, and lobe degeneration: clinical, neuropsychological,

15 Pickut BA, Saerens J, Marien P, et al. Discriminative use of Pickut BA, Saerens J, Marien P, et al. Discriminative use of
SPECT in frontal lobe-type dementia versus (senile) dementia of the Alzheimer's type. F Nucl Med 1997;38: 929-34

16 Miller BL, Ikonte C, Ponton M, et al. A study of the LundManchester research criteria for frontotemporal dementia: clinical and single-photon emission CT correlations. Neurology 1997;48:937-42.

17 Goto R, Kawashima R, et al. A comparison of Tc-99m HMPAO brain SPECT images of young and aged normal individuals. Ann Nucl Med 1998;12:333-9. Nucl Med 1999;40:956-62. 